\title{
A Direct Observation of a Concerted Two-Bond Breaking Reaction
}

\author{
Jr-Wei Ho, Wei-Kan Chen and Po-Yuan Cheng* \\ Department of Chemistry, National Tsing Hua University, Hsinchu, Taiwan 30043
}

\section{Supporting Information}

\section{Experimental details}

The experimental setup is similar to those described in our previous works. ${ }^{1-3}$ The femtosecond (fs) laser system consists of a self-mode-locked Ti:sapphire laser (Spectra Physics, Tsunami), a $1 \mathrm{kHz}$ chirped-pulse regenerative amplifier (CPA, Spectra Physics, Spitfire) and a five-pass optical parametric generator/amplifier (Light Conversion, TOPAS). The fs-laser pulses used in this work were obtained through harmonic generation and frequency mixing of the outputs from this laser system.

The fs-LIF experiment for probing the SO product was carried out in a gas flow cell that is constantly pumped by an oil-free pump. DMSO vapor was slowly flowed into the cell through a needle valve to maintain a pressure of $\sim 120$ mtorr. DMSO was excited at $\sim 200 \mathrm{~nm}$ and a second delayed pulse at $\sim 240-260 \mathrm{~nm}$ was used to probe the temporal evolution of the free $\mathrm{SO}(\mathrm{X})$ fragments by monitoring the $\mathrm{SO} \mathrm{X} \rightarrow \mathrm{B}$ laser-induced fluorescence (LIF) signal. Different SO (X) vibrational levels $\left(\mathrm{v}^{\prime \prime}=1,2,3\right)$ can be selectively monitored by tuning the probe lasers to the corresponding wavelengths..$^{4-6}$ The pump and probe beams were collinearly recombined via a dichroic mirror and focused through a $f=50 \mathrm{~cm}$ lens into the gas cell. The laser-induced fluorescence of SO fragments was collected at right angle and detected by a photomultiplier tube. A bandpass filter centered at $330 \mathrm{~nm}$ and two long-pass filters (290 nm cutoff) were placed in the light collection system to further reduce the scattered light and to ensure that only photons in the $300-370 \mathrm{~nm}$ spectral region ( $\mathrm{SO} \mathrm{B} \rightarrow \mathrm{X}$ 
fluorescence) can be efficiently detected. The signal from the photomultiplier tube was then sent to a boxcar gate integrator for signal averaging. The boxcar gate was typically $50 \mathrm{nsec}$ in duration and was delayed from the laser pulse to avoid interference from the scattered light. The transients were obtained by monitoring the fluorescence signal as a function of the pump-probe delay time.

We assigned the observed transient fluorescence signal to the free $\mathrm{SO}(\mathrm{X})$ fragments arising from DMSO photodissociation on the bases of following reasons: (1) When the probe-laser wavelength was tuned across the spectral region from $240 \mathrm{~nm}$ to $260 \mathrm{~nm}$, the fluorescence intensity variation as a function of the probe-laser wavelength is consistent with the reported SO $X \rightarrow$ B LIF excitation spectra. ${ }^{4,5}$ (2) The spectral filters used in the light collection system allowed only photons in the spectral region of $300-370 \mathrm{~nm}$, which coincides with SO B $\rightarrow \mathrm{X}$ fluorescence, ${ }^{6}$ to enter the photomultiplier tube. (3) The observed fluorescence lifetime is 20 30 nsec, consistent with the literature values for the SO B state. ${ }^{6}$ (4) Laser-irradiance dependence studies indicated that the observed LIF transients are indeed due to one-photon absorption of the pump and probe lasers. These combined evidence and reasoning unambiguously indicate that the observed transient fluorescence is due to free SO (X) produced in the DMSO photodissociation.

The fs-REMPI experiment for the $\mathrm{CH}_{3}$ product probing was carried out in a conventional two-chamber differentially pumped molecular beam apparatus equipped with a time-of-flight mass spectrometer (TOF-MS). A saturated $\mathrm{DMSO} / \mathrm{He}$ gas mixture at room temperature was expanded through a $100 \mu \mathrm{m}$ diameter pinhole to produce a continuous supersonic jet in the first chamber. The nozzle was heated to $\sim 100{ }^{\circ} \mathrm{C}$ to avoid cluster formation. The jet was skimmed before entering the second chamber where it was intersected by the fs laser pulses in the extraction region of the TOF-MS. DMSO in the jet was excited at $200 \mathrm{~nm}$ and the 
methyl products were probed using $2+1$ REMPI detection via the $\mathrm{CH}_{3} 3 \mathrm{p}^{2} A_{2} " \leftarrow 2 \mathrm{p}^{2} A_{2} " 0_{0}^{0}$ transition at $333.5 \mathrm{~nm}$. The pump and probe beams were collinearly focused through a $f=50$ cm lens into the extraction region of TOF-MS. Fs mass-selected transients were obtained by monitoring the ion intensity at the $\mathrm{CH}_{3}$ mass channel with a boxcar integrator while the pump vs. probe delay time was scanned. For all transients presented here the angle between the pump- and probe-laser polarizations was set at the magic angle $\left(54.7^{\circ}\right)$ to minimize the rotational coherence effect. Pulse energies were kept low $(<0.5 \mu \mathrm{J} /$ pulse $)$ for the pump laser to ensure one-photon excitation; while slightly higher pulse energies were used for the probe to facilitate the REMPI detection.

For both experiments the transients were fitted to suitable kinetic models convoluted with Gaussian instrument response functions using a nonlinear least square fitting procedure. The effective cross correlation of the pump and probe was 250 fs FWHM in the fs-LIF experiment and $230 \mathrm{fs}$ in the fs-REMPI experiment.

\section{Calculation Methods}

All calculations were performed using the Gaussian 03 program. ${ }^{4}$ We first calculated the ground-state optimized structures and their corresponding energies as a function of C-S bond lengths at the UB3LYP/6-311G(d) level of theory. For the single C-S bond breaking only one C-S bond length was fixed at the value of interest while all other geometric parameters were optimized. The ground-state energy was then recalculated at the UQCISD(T)/6-311G(d) level using the pre-optimized structure. More than 20 different C-S bond lengths ranging from $1.6 \AA$ to $4 \AA$ were calculated in order to depict the calculated ground-state minimum-energy path (MEP). Similar procedures were carried out for the concerted 
breaking of both C-S bonds, except that now the lengths of the two C-S bonds were kept at the same value of interest while others were optimized. The vertical excitation energy of each optimized structure along the ground-state MEP was then calculated at the TD-B3LYP/6-311++G(3df,2p) level of theory. Note that the excited-state potential energy curve thus obtained is merely a cross section of the global potential energy surface along the calculated ground-state MEP.

(1) Lee, I. R.; Chung, Y. C.; Chen, W. K.; Hong, X. P.; Cheng, P. Y., J. Chem. Phys. 2001, 115, 10656-10670.

(2) Chen, W. K.; Ho, J. W.; Cheng, P. Y., J. Phys. Chem. A 2005, 109, 6805-6817.

(3) Chen, W. K.; Ho, J. W.; Cheng, P. Y., J. Phys. Chem. A 2005, 109, 6818-6829.

(4) Chen, X. R.; Wang, H. X.; Weiner, B. R.; Hawley, M.; Nelson, H. H., J. Phys. Chem. 1993, 97, 12269-12274.

(5) Thorson, G. M.; Cheatum, C. M.; Coffey, M. J.; Crim, F. F., J. Chem. Phys. 1999, 110, 10843-10849.

(6) Yamasaki, K.; Taketani, F.; Tomita, S.; Sugiura, K.; Tokue, I., J. Phys. Chem. A 2003, 107, 2442-2447.

(7) Gaussian 03, Revision B.01, Frisch, M. J.; Trucks, G. W.; Schlegel, H. B.; Scuseria, G. E.; Robb, M. A.; Cheeseman, J. R.; Montgomery, J. A.; Vreven, Jr., T.; Kudin, K. N.; Burant, J. C.; Millam, J. M.; Iyengar, S. S.; Tomasi, J.; Barone, V.; Mennucci, B.; Cossi, M.; Scalmani, G.; Rega, N.; Petersson, G. A.; Nakatsuji, H.; Hada, M.; Ehara, M.; Toyota, K.; Fukuda, R.; Hasegawa, J.; Ishida, M.; Nakajima, T.; Honda, Y.; Kitao, O.; Nakai, H.; Klene, M.; Li, X.; Knox, J. E.; Hratchian, H. P.; Cross, J. B.; Adamo, C.; Jaramillo, J.; Gomperts, R.; Stratmann, R. E.; Yazyev, O.; Austin, A. J.; Cammi, R.; Pomelli, C.; Ochterski, J. W.; Ayala, P. Y.; Morokuma, K.; Voth, G. A.; Salvador, P.; Dannenberg, J. J.; Zakrzewski, V. G.; Dapprich, S.; Daniels, A. D.; Strain, M. C.; Farkas, O.; Malick, D. K.; Rabuck, A. D.; Raghavachari, K.; Foresman, J. B.; Ortiz, J. V.; Cui, Q.; Baboul, A. G.; Clifford, S.; Cioslowski, J.; Stefanov, B. B.; Liu, G.; Liashenko, A.; Piskorz, P.; Komaromi, I.; Martin, R. L.; Fox, D. J.; Keith, T.; Al-Laham, M. A.; Peng, C. Y.; Nanayakkara, A.; Challacombe, M.; Gill, P. M. W.; Johnson, B.; Chen, W.; Wong, M. W.; Gonzalez, C.; Pople, J. A., Gaussian, Inc., Pittsburgh PA, 2003. 